\title{
Ipragliflozin Improves Glycemic Control and Decreases Body Fat in Patients With Type 2 Diabetes Mellitus
}

\author{
Takehiro Kawata $^{\mathrm{a}}$, Takashi Iizuka ${ }^{\mathrm{a}}$, Kotaro Iemitsu ${ }^{\mathrm{a}}$, Masahiro Takihata ${ }^{\mathrm{a}}$, Masahiko Takai ${ }^{\mathrm{a}}$, \\ Shigeru Nakajima ${ }^{a}$, Nobuaki Minami ${ }^{\mathrm{a}}$, Shinichi Umezawa ${ }^{\mathrm{a}}$, Akira Kanamoria, Hiroshi Takeda ${ }^{\mathrm{a}}$, \\ Shogo Ito ${ }^{\text {a }}$ Taisuke Kikuchia, Hikaru Amemiya ${ }^{a}$, Mizuki Kaneshiro ${ }^{\text {a }}$, Atsuko Mokubo ${ }^{a}$, \\ Tetsuo Takuma ${ }^{a}$, Hideo Machimura ${ }^{\text {a }}$, Keiji Tanaka ${ }^{a}$, Taro Asakura ${ }^{a}$, Akira Kubota ${ }^{a}$, Sachio Aoyanagia, \\ Kazuhiko Hoshino a, Masashi Ishikawa ${ }^{a}$, Yoko Matsuzawa ${ }^{a}$, Mitsuo Obana ${ }^{a}$, Nobuo Sasai ${ }^{a}$, \\ Hideaki Kaneshige ${ }^{a}$, Fuyuki Minagawa ${ }^{a}$, Tatsuya Saito ${ }^{a}$, Kazuaki Shinoda ${ }^{a}$, Masaaki Miyakawa ${ }^{a}$, \\ Yasushi Tanaka ${ }^{b}$, Yasuo Terauchic, Ikuro Matsuba ${ }^{a, d}$
}

\begin{abstract}
Background: Ipragliflozin, a sodium-glucose transporter 2 inhibitor, was administered to patients with type 2 diabetes mellitus for 24 weeks to evaluate its effect on glycemic control and body composition.

Methods: This was an investigator-initiated multicenter prospective intervention study in which ipragliflozin $(50 \mathrm{mg})$ was administered once daily and glycemic control, blood pressure, body weight (BW), body composition (measured by a biological impedance method), the lipid profile, and adverse events were evaluated after 4, 12, and 24 weeks of treatment.
\end{abstract}

Results: Efficacy and safety up to 24 weeks of ipragliflozin therapy were analyzed in 367 patients and 451 patients, respectively. Hemoglobin A1c decreased significantly from $8.07 \%$ at the start of ipragliflozin therapy to $7.26 \%$ in week $24(\mathrm{P}<0.001)$. Fasting and postprandial blood glucose levels were significantly reduced by ipragliflozin. In week 24, there were significant decreases from baseline in BW $(-2.6 \mathrm{~kg})$, waist circumference $(-2.9 \mathrm{~cm})$, and body fat mass $(-1.9 \mathrm{~kg})$ $(\mathrm{P}<0.001)$. The body water mass and mineral mass were decreased significantly by 0.5 and by $0.1 \mathrm{~kg}$, respectively $(\mathrm{P}<0.001)$, whereas the protein mass did not change significantly. Intracellular water mass did not change significantly, whereas extracellular water mass

Manuscript accepted for publication April 11, 2017

aDiabetes Committee, Kanagawa Physicians Association, 3-1 Fujimi-cho, Naka-ku, Yokohama-shi, Kanagawa 231-0037, Japan

bDepartment of Internal Medicine, Division of Metabolism and Endocrinology, St. Marianna University School of Medicine, 2-16-1 Sugao, Miyamae-ku, Kawasaki-shi, Kanagawa 216-8511, Japan

'Department of Molecular Endocrinology and Diabetic Internal Medicine, Yokohama City University Graduate School of Medicine, 3-9 Fukuura, Kanazawa-ku, Yokohama-shi, Kanagawa 236-0004, Japan

${ }^{\mathrm{d} C o r r e s p o n d i n g ~ A u t h o r: ~ I k u r o ~ M a t s u b a, ~ M a t s u b a ~ M e d i c a l ~ C l i n i c, ~ 2-159 ~ T s u k-~}$ agoshi, Saiwai-ku, Kawasaki-shi, Kanagawa 212-0024, Japan.

Email: ikuro@matsuba-web.com

doi: https://doi.org/10.14740/jocmr3038w showed a significant decrease of $0.5 \mathrm{~kg}(\mathrm{P}<0.001)$. Muscle mass did not change in the upper and lower limbs, but that of the trunk decreased significantly $(\mathrm{P}<0.001)$. There was a significant decrease in the fasting triglyceride level and a significant increase in fasting high-density lipoprotein cholesterol level, while low-density lipoprotein cholesterol was unchanged. Adverse events occurred in $23.5 \%$ of the patients, with a high frequency of genital infections, such as vulvovaginal candidiasis (3.1\%) and genital pruritus (1.8\%). Adverse drug reactions were noted in $13.7 \%$ of the patients.

Conclusions: Administration of ipragliflozin for 24 weeks improved glycemic control and decreased BW. Reduction of body fat accounted for more than $70 \%$ of the total weight loss and reduction of extracellular water accounted for about $20 \%$.

Keywords: Body fat mass; Sodium-glucose cotransporter 2 inhibitor; Ipragliflozin; Type 2 diabetes mellitus; Glycemic control

\section{Introduction}

Sodium-glucose transporter 2 (SGLT2) inhibitors are drugs for the treatment of type 2 diabetes mellitus (T2DM) that increase urinary glucose excretion by inhibiting glucose reabsorption in the proximal tubules of the kidney and thus reduce the blood glucose (BG) level [1]. The mechanism of action differs from other medications for diabetes since SGLT2 inhibitors do not have any effect on insulin secretion by $\beta$ cells in the pancreas. Therefore, the risk of hypoglycemia is low with SGLT2 inhibitor monotherapy and these drugs can also be used concomitantly with other antidiabetic medications [2, 3]. SGLT2 inhibitors also have pleiotropic effects that include reduction of body weight (BW), reduction of blood pressure (BP), and improvement of the serum lipid profile (elevation of high-density lipoprotein (HDL) cholesterol and reduction of triglycerides) [4]. Regarding safety, there is a lower risk of hypoglycemia with SGLT2 inhibitors than sulfonylureas (SUs) and the risk is similar to that for biguanides, thiazolidinediones (TZDs), and dipeptidyl peptidase 4 (DPP-4) 
inhibitors. Urinary tract and genital infections show an increase in patients taking SGLT2 inhibitors, particularly in women [5].

Ipragliflozin is an SGLT2 inhibitor that was approved in Japan in 2014 [6]. It was reported that both ipragliflozin monotherapy $[7,8]$ and combination therapy with other antidiabetic agents [9-11] improve glycemic control and decrease BW in patients with T2DM. However, there are still insufficient clinical data about the efficacy and safety of ipragliflozin obtained from long-term large-scale studies in the real-world clinical setting. In particular, with regard to the effect of ipragliflozin on BW, to our knowledge, there has been no prospective detailed observation of changes in body composition measured in multiple centers.

In the ASSIGN-K study, ipragliflozin was administered to Japanese patients with T2DM who showed poor glycemic control after management with diet and exercise alone or diet and exercise plus antidiabetic agents other than ipragliflozin for at least 12 weeks, and the interim results for efficacy and safety based on data obtained after 12 weeks of ipragliflozin therapy have been reported [12]. The present study was performed to investigate changes in body composition measured by a biological impedance method from baseline to 24 weeks after initiation of ipragliflozin therapy in the ASSIGN-K patient population.

\section{Patients and Methods}

\section{Study design}

The ASSIGN-K study was an investigator-initiated prospective multicenter intervention trial that assessed the efficacy and the safety of ipragliflozin in Japanese patients with T2DM. Subjects were enrolled at 33 sites in Japan by using an electronic data capture system from July 2014 to January 31, 2016. Before enrollment, all of the patients were provided with detailed information about this study and gave written informed consent. After enrollment, treatment with ipragliflozin was initiated at $50 \mathrm{mg}$ once daily before or after breakfast. Patients visited the participating hospital for assessment at the start of ipragliflozin therapy and after 4, 12, and 24 weeks of treatment. We previously reported the interim results for the primary endpoint and adverse events (AEs) after 12 weeks of ipragliflozin therapy [12].

This study was conducted in accordance with the principles of the Declaration of Helsinki and the Ethical Guidelines for Clinical Research. The study protocol and the informed consent document were approved by the institutional review boards of the participating hospitals before initiation of the investigation. This study was registered with the University Hospital Medical Information Network Clinical Trials Registry (no.: UMIN000014425).

\section{Patients}

As reported previously [12], the key inclusion criteria were: 1) men or women aged 20 years or older with T2DM; 2) patients with poor glycemic control despite receiving treatment for at least 12 weeks with diet and exercise alone or diet and exercise plus an antidiabetic agent; and 3) patients whose hemoglobin A1c (HbA1c) (National Glycohemoglobin Standardization
Program) was $6.0 \%$ or higher. Key exclusion criteria were as follows: 1) a history of hypersensitivity to any component of the study drug; 2) a history of severe ketosis, diabetic coma, or precoma within 6 months before enrollment; 3) severe infection, preoperative or postoperative status, or serious injury; and 4) severe renal dysfunction.

\section{Efficacy evaluation}

Efficacy was evaluated by assessing the changes from the baseline in $\mathrm{HbAlc}$, fasting and post-prandial BG, BW, waist circumference (WC), serum lipids, free fatty acids, BP, and body composition [12]. Body composition analysis was performed by a biological impedance method using a T-Scan Plus (Kobe Medicare Corporation, Kobe, Japan) to determine the following parameters: BW, body mass index (BMI), percent body fat, abdominal obesity ratio, fat-free body mass, body fat mass (BFM), muscle mass of the upper limbs, lower limbs, and trunk, mineral mass, protein mass, body water mass, intracellular water mass, and extracellular water mass.

\section{Safety evaluation}

Safety was evaluated by assessing the change in blood ketone bodies from baseline, as well as AEs and adverse drug reactions (ADRs) [12]. AEs were coded according to the Medical Dictionary for Regulatory Activities (MedDRA) Japanese version 18.0 (Japanese Maintenance Organization, Tokyo, Japan).

\section{Statistical analysis}

Baseline characteristics of the patients were expressed as the mean with standard deviation for continuous variables and as percentages for categorical variables. Repeated-measures analysis of variance was performed to investigate the changes from baseline to week 4, week 12, and week 24. Subgroup analysis was carried out using mixed models in which the groups, time points, and interaction between groups and time points were fixed effects and the patients were a random effect. The covariance structure was compound symmetry, and the degree of freedom was adjusted by using the Kenward-Roger method. In all analyses, the level of significance was set at 5\% (two-tailed) and multiplicity was adjusted by Tukey's method. When confidence intervals were calculated, the confidence level was set at $95 \%$ (two-tailed). Statistical analyses were carried out using SAS software (version 9.4; SAS Institute, Cary, NC, USA). The number and percentage of patients with AEs in the analysis set were determined.

\section{Results}

\section{Baseline characteristics of the patients}

Baseline characteristics of the 451 patients in the safety anal- 
Table 1. Baseline Characteristics of the Patients

\begin{tabular}{|c|c|c|}
\hline & n (\%) & Mean \pm standard deviation \\
\hline \multicolumn{3}{|l|}{ Gender } \\
\hline Male & $234(51.9)$ & \\
\hline Female & $217(48.1)$ & \\
\hline Age, years & $451(100.0)$ & $55.5 \pm 11.6$ \\
\hline Body weight, $\mathrm{kg}$ & $451(100.0)$ & $78.6 \pm 16.8$ \\
\hline Body mass index, $\mathrm{kg} / \mathrm{m}^{2}$ & $451(100.0)$ & $29.4 \pm 5.3$ \\
\hline$<25$ & $84(18.6)$ & \\
\hline$\geq 25$ to $<30$ & $191(42.4)$ & \\
\hline$\geq 30$ & $176(39.0)$ & \\
\hline Waist circumference, $\mathrm{cm}$ & $451(100.0)$ & $99.8 \pm 12.0$ \\
\hline Duration of diabetes, years & $451(100.0)$ & $9.6 \pm 7.4$ \\
\hline \multicolumn{3}{|l|}{ Complications of diabetes } \\
\hline Diabetic nephropathy & $131(29.0)$ & \\
\hline Diabetic retinopathy & $62(13.7)$ & \\
\hline Diabetic neuropathy & $60(13.3)$ & \\
\hline \multicolumn{3}{|l|}{ Concomitant diseases } \\
\hline Dyslipidemia & $294(65.2)$ & \\
\hline Hypertension & $259(57.4)$ & \\
\hline Fatty liver & $218(48.3)$ & \\
\hline Cataract & $76(16.9)$ & \\
\hline \multicolumn{3}{|l|}{ Prescribing status } \\
\hline Naive & $79(17.5)$ & \\
\hline Concomitant use & $335(74.3)$ & \\
\hline Switching & $37(8.2)$ & \\
\hline \multicolumn{3}{|l|}{ Concomitant antidiabetic therapy } \\
\hline Dipeptidyl peptidase 4 inhibitor & $245(73.1)$ & \\
\hline Biguanide & $216(64.5)$ & \\
\hline Sulfonylurea & $123(36.7)$ & \\
\hline Insulin & $72(21.5)$ & \\
\hline Thiazolidinedione & $46(13.7)$ & \\
\hline$\alpha$-glucosidase inhibitor & $33(9.9)$ & \\
\hline Glinide & $16(4.8)$ & \\
\hline Glucagon-like peptide 1 analogue & $4(1.2)$ & \\
\hline Others & $26(7.8)$ & \\
\hline
\end{tabular}

ysis set are shown in Table 1. There were 234 men (51.9\%) and 217 women (48.1\%). The mean age was $55.5 \pm 11.6$ years and the mean duration of diabetes was $9.6 \pm 7.4$ years. BW was $78.6 \pm 16.8 \mathrm{~kg}$, BMI was $29.4 \pm 5.3 \mathrm{~kg} / \mathrm{m}^{2}$, and WC was 99.8 $\pm 12.0 \mathrm{~cm}$. Other antidiabetic medications were used concomitantly with ipragliflozin by $74.3 \%$ of the patients, including DPP-4 inhibitors in 245 patients $(73.1 \%)$, biguanides in 216 patients $(64.5 \%)$, SUs in 123 patients $(36.7 \%)$, insulin in 72 patients $(21.5 \%)$, TZDs in 46 patients $(13.7 \%), \alpha$-glucosidase inhibitors in 33 patients $(9.9 \%)$, glinides in 16 patients $(4.8 \%)$, and glucagon-like peptide 1 analogs in four patients $(1.2 \%)$. Nearly all of the patients had concomitant diseases $(425 / 451$, $94.2 \%)$. The most frequent concomitant disease was dyslipidemia in $65.2 \%(\mathrm{n}=294)$, while other concomitant diseases included hypertension in $57.4 \%(\mathrm{n}=259)$ and fatty liver in $48.3 \%(n=218)$. Complications of diabetes included diabetic nephropathy in $29.0 \%(\mathrm{n}=131)$, diabetic retinopathy in $13.7 \%$ $(n=62)$, and diabetic neuropathy in $13.3 \%(n=60)$. 
Table 2. Changes in Glycemic Control Parameters from Initiation of Ipragliflozin Therapy

\begin{tabular}{|c|c|c|c|c|c|}
\hline & n & Week 0 & Week 4 & Week 12 & Week 24 \\
\hline Hemoglobin A1c, \% & 374 & $8.07 \pm 1.46$ & $\begin{array}{l}7.66 \pm 1.22 * * * \\
(-0.41 \pm 0.60)\end{array}$ & $\begin{array}{l}7.31 \pm 1.11 * * * \\
(-0.76 \pm 1.07)\end{array}$ & $\begin{array}{l}7.26 \pm 1.05^{* * *} \\
(-0.81 \pm 1.11)\end{array}$ \\
\hline Fasting blood glucose, $\mathrm{mg} / \mathrm{dL}$ & 114 & $156.0 \pm 44.6$ & $\begin{array}{l}136.7 \pm 36.8 * * * \\
(-19.3 \pm 37.7)\end{array}$ & $\begin{array}{l}132.2 \pm 33.4 * * * \\
(-23.8 \pm 35.2)\end{array}$ & $\begin{array}{l}136.0 \pm 33.2 * * * \\
(-20.0 \pm 38.0)\end{array}$ \\
\hline Postprandial blood glucose, $\mathrm{mg} / \mathrm{dL}$ & 137 & $184.7 \pm 74.0$ & $\begin{array}{l}156.9 \pm 58.7 * * * \\
(-27.8 \pm 74.6)\end{array}$ & $\begin{array}{l}153.4 \pm 62.6^{* * *} \\
(-31.3 \pm 70.9)\end{array}$ & $\begin{array}{l}147.3 \pm 49.5^{* * *} \\
(-37.4 \pm 76.7)\end{array}$ \\
\hline $\begin{array}{l}\text { Homeostatic model assessment of } \\
\text { insulin resistance }\end{array}$ & 51 & $4.46 \pm 3.69$ & $\begin{array}{l}3.14 \pm 2.27 * * \\
(-1.32 \pm 2.83)\end{array}$ & $\begin{array}{l}3.16 \pm 2.36 * * * \\
(-1.30 \pm 1.96)\end{array}$ & $\begin{array}{l}3.28 \pm 2.70 * * \\
(-1.18 \pm 2.11)\end{array}$ \\
\hline $\begin{array}{l}\text { Homeostatic model assessment of } \\
\text { beta cell function }\end{array}$ & 51 & $46.49 \pm 44.66$ & $\begin{array}{l}50.70 \pm 44.66 \\
(4.21 \pm 26.69)\end{array}$ & $\begin{array}{l}52.94 \pm 43.05 \\
(6.45 \pm 24.39)\end{array}$ & $\begin{array}{l}49.48 \pm 43.55 \\
(2.99 \pm 20.15)\end{array}$ \\
\hline Insulin, $\mu \mathrm{U} / \mathrm{mL}$ & 51 & $12.65 \pm 9.06$ & $\begin{array}{l}11.82 \pm 9.60 \\
(-0.84 \pm 7.69)\end{array}$ & $\begin{array}{l}13.89 \pm 21.07 \\
(1.24 \pm 16.82)\end{array}$ & $\begin{array}{l}12.42 \pm 13.60 \\
(-0.23 \pm 9.84)\end{array}$ \\
\hline C-peptide immunoreactivity, $\mathrm{ng} / \mathrm{mL}$ & 51 & $3.123 \pm 2.060$ & $\begin{array}{l}3.348 \pm 2.793 \\
(0.224 \pm 2.553)\end{array}$ & $\begin{array}{l}3.120 \pm 2.283 \\
(-0.004 \pm 1.813)\end{array}$ & $\begin{array}{l}3.073 \pm 2.026 \\
(-0.050 \pm 1.907)\end{array}$ \\
\hline
\end{tabular}

Data are shown as the mean \pm standard deviation. Analysis of variance vs. week $0,{ }^{* *} \mathrm{P}<0.001,{ }^{* *} \mathrm{P}<0.01$.

\section{Efficacy evaluation}

\section{Glycemic control}

The efficacy analysis set included 367 patients who received ipragliflozin for 24 weeks. In these patients, the change in HbAlc from baseline in week 4 , week 12, and week 24 was $-0.41 \%$, $-0.76 \%$, and $-0.81 \%$, respectively, and $\mathrm{HbA} 1 \mathrm{c}$ was decreased significantly at all time points $(\mathrm{n}=367 ; \mathrm{P}<0.001)$ (Table 2). In the efficacy analysis set, the percentage of patients with an $\mathrm{HbA} 1 \mathrm{c}$ of less than $7 \%$ (reference value) increased from $14.6 \%$ in week 4 of ipragliflozin treatment to $29.9 \%$ in week 12 and $33.3 \%$ in week 24 (data not shown). The change in the fasting BG level and postprandial BG level from the start of ipragliflozin therapy in week 24 was -20.0 and $-37.4 \mathrm{mg} / \mathrm{dL}$, respectively, with both parameters showing a significant decrease $(\mathrm{P}<0.001)$. Insulin and C-peptide immunoreactivity were also decreased in week 24 compared with baseline, but showed no significant changes throughout the administration period. Homeostasis model assessment of insulin resistance displayed a significant decrease after 4 weeks of ipragliflozin therapy and this decrease was maintained until 24 weeks $(\mathrm{P}<0.01)$. Homeostasis model assessment of beta-cell function (HOMA- $\beta$ ) revealed an increase after 4 weeks of ipragliflozin therapy, but there was no significant change in HOMA- $\beta$ throughout the administration period.

\section{$B W, W C$, and body composition}

The change in BW from the start of ipragliflozin therapy was $-1.2 \mathrm{~kg}$ in week $4,-2.1 \mathrm{~kg}$ in week 12 , and $-2.6 \mathrm{~kg}$ in week 24 , showing significant weight loss $(\mathrm{P}<0.001)$ (Fig. 1a). The percent change in $\mathrm{BW}$ from the start of ipragliflozin therapy was $-1.5 \%$ in week $4,-2.6 \%$ in week 12 , and $-3.2 \%$ in week 24 . There was at least $5 \%$ reduction of BW in $2.4 \%$ of the patients in week 4 , increasing to $14.6 \%$ of the patients in week 12 and to $23.4 \%$ in week 24 (data not shown). The change in
WC from the start of ipragliflozin therapy was $-1.0 \mathrm{~cm}(\mathrm{P}<$ $0.01)$ in week $4,-1.9 \mathrm{~cm}(\mathrm{P}<0.001)$ in week 12 , and $-2.9 \mathrm{~cm}$ $(\mathrm{P}<0.001)$ in week 24 , demonstrating a significant decrease (Fig. 1b). The patients were classified into two groups with or without concomitant use of an SU, TZD, or insulin to perform stratified analyses of the changes in BW and WC. It was found that $\mathrm{BW}$ and WC both showed a significant decrease in week 24 compared with the baseline values in the two groups (both $\mathrm{P}$ $<0.001$ ) (Fig. 1c, d). The changes were larger in patients without concomitant therapy (SU, TZD, or insulin) than in patients receiving concomitant treatment with one of these drugs, but there was no significant difference between the groups.

Changes in body composition after initiation of ipragliflozin therapy are shown in Table 3 . The change in BFM from the start of administration was $-0.7 \mathrm{~kg}$ in week $4,-1.4 \mathrm{~kg}$ in week 12 , and $-1.9 \mathrm{~kg}$ in week $24(\mathrm{P}<0.001)$, displaying a significant decrease. The fat-free body mass (sum of the muscle mass and the mineral mass) decreased significantly by $0.5 \mathrm{~kg}$ in week 4 , $0.7 \mathrm{~kg}$ in week 12 , and $0.6 \mathrm{~kg}$ in week $24(\mathrm{P}<0.001)$. Changes in the muscle mass and mineral mass were respectively $-0.4 \mathrm{~kg}$ and $-0.1 \mathrm{~kg}$ in week $4(\mathrm{P}<0.001),-0.6 \mathrm{~kg}$ and $-0.1 \mathrm{~kg}$ in week $12(\mathrm{P}<0.001)$, and $-0.5 \mathrm{~kg}(\mathrm{P}<0.01)$ and $-0.1 \mathrm{~kg}(\mathrm{P}<0.001)$ in week 24, and both the muscle mass and mineral mass (components of the fat-free body mass) decreased significantly.

The change in body water mass (a component of the muscle mass) was $-0.4 \mathrm{~kg}$ in week $4,-0.5 \mathrm{~kg}$ in week 12 , and -0.5 $\mathrm{kg}$ in week 24, with body water showing a significant decrease at all time points $(\mathrm{P}<0.001)$. However, the protein mass did not show a significant change at week 24 . Regarding the components of body water mass, the change in the extracellular water mass from the start of treatment was $-0.3 \mathrm{~kg}$ in week 4 , $-0.6 \mathrm{~kg}$ in week 12 , and $-0.5 \mathrm{~kg}$ in week 24 , revealing a significant decrease at all time points $(\mathrm{P}<0.001)$. In contrast, the intracellular water mass did not change significantly. Analysis of the muscle mass by anatomical site showed that were no significant changes in the muscle mass of the upper limbs and the lower limbs in week 24. However, the muscle mass of the trunk showed a significant decrease by $0.2 \mathrm{~kg}$ in week $4,0.3 \mathrm{~kg}$ 


\section{a}

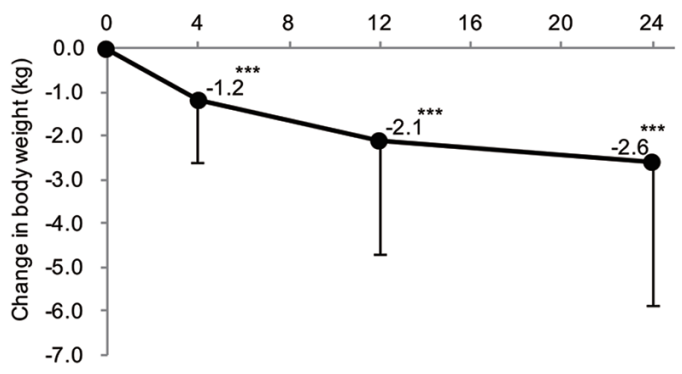

$\mathrm{C}$

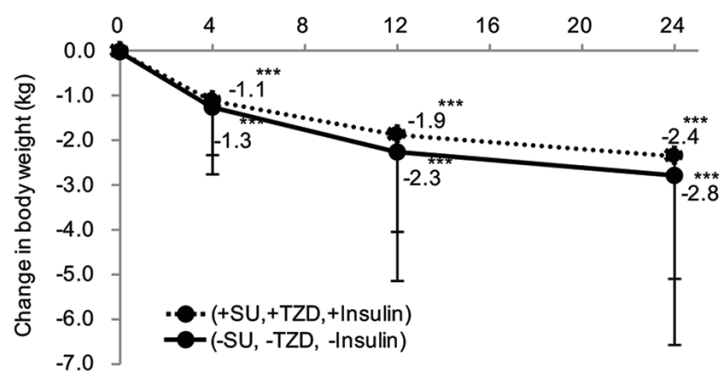

b
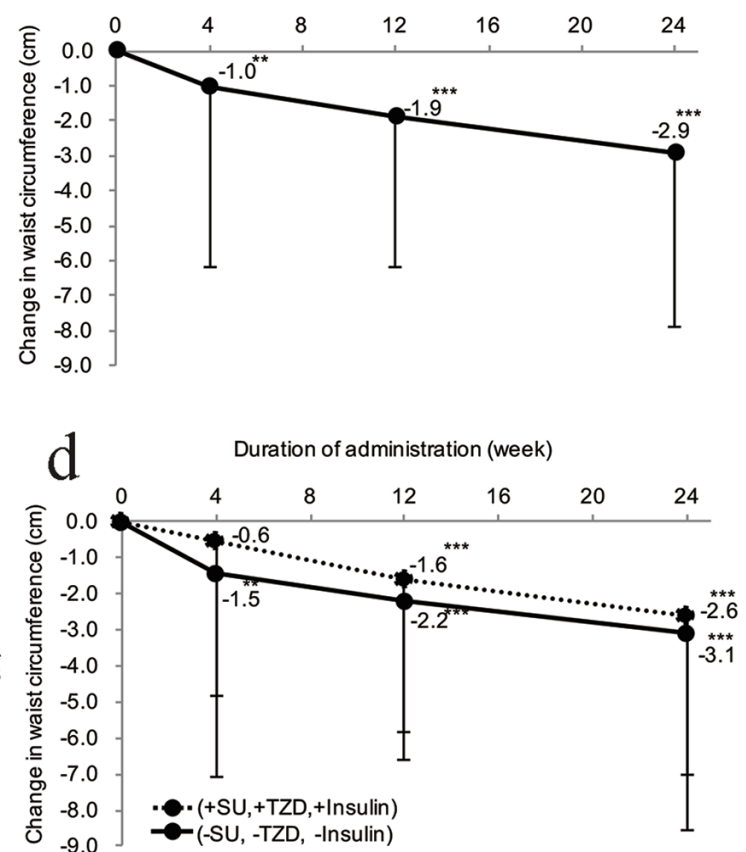

Figure 1. Effect of ipragliflozin on body weight and waist circumference. (a) Change in body weight after the start of ipragliflozin therapy $(n=295)$. (b) Change in waist circumference after the start of ipragliflozin therapy $(n=334)$. (c) Stratified analysis of the body weight changes in patients receiving ipragliflozin concomitantly with an SU, insulin, or TZD $(n=152)$ and patients receiving ipragliflozin without concomitant use of these drugs $(n=143)$. (d) Stratified analysis of the waist circumference changes in patients receiving ipragliflozin concomitantly with an SU, insulin, or TZD $(n=171)$ and patients receiving ipragliflozin without concomitant use of these drugs $(n=163)$. (e) Changes in body fat mass and fat-free body mass measured by a body composition analyzer from the start of ipragliflozin administration (body fat mass, $n=295$; fat-free body mass, $n=295$ ). (f) Changes in body composition measured by a body composition analyzer from the initiation of ipragliflozin treatment. Significant differences in week 4, week 12, and week 24 relative to the start of administration: ${ }^{* *} \mathrm{P}<0.001$; ${ }^{* *} \mathrm{P}<0.01$; ${ }^{*} \mathrm{P}<0.05$, respectively. SU: sulfonylurea; TZD: thiazolidinedione.

in week 12 , and $0.3 \mathrm{~kg}$ in week $24(\mathrm{P}<0.001)$.

The change in BMI from initiation of ipragliflozin therapy was $-0.4 \mathrm{~kg} / \mathrm{m}^{2}$ in week $4,-0.8 \mathrm{~kg} / \mathrm{m}^{2}$ in week 12 , and $-1.0 \mathrm{~kg} /$ $\mathrm{m}^{2}$ in week 24 , revealing that BMI decreased significantly $(\mathrm{P}$ $<0.001)$. Percent body fat showed a significant decrease after 4 weeks of ipragliflozin therapy $(\mathrm{P}<0.01)$, and decreased further at 24 weeks $(\mathrm{P}<0.001)$. The abdominal obesity ratio (visceral fat/subcutaneous fat ratio) demonstrated a significant decrease in week $4(\mathrm{P}<0.01)$, week $12(\mathrm{P}<0.001)$, and week $24(\mathrm{P}<0.001)$ after the start of ipragliflozin therapy.

\section{Clinical test values}

Changes in the BP and fasting serum lipid levels after the initiation of ipragliflozin therapy are shown in Table 4 . The change in the systolic BP and diastolic BP was -5.1 and $-2.6 \mathrm{~mm} \mathrm{Hg}$ in week 4 , respectively, showing a significant decrease $(\mathrm{P}<$ 0.001 ) that was maintained until week 24.

There were no significant changes in total cholesterol and low-density lipoprotein (LDL) cholesterol at any of the time points during administration of ipragliflozin. HDL cholesterol was increased by $5.1 \mathrm{mg} / \mathrm{dL}$ in week 24 of administration, and this increment was significant $(\mathrm{P}<0.001)$. The change in the triglyceride level from the start of ipragliflozin therapy was $-18.5 \mathrm{mg} / \mathrm{dL}$ in week $4,-23.4 \mathrm{mg} / \mathrm{dL}$ in week 12 , and -27.3 $\mathrm{mg} / \mathrm{dL}$ in week 24 , showing a significant decrease at each time point ( $\mathrm{P}<0.05, \mathrm{P}<0.01$, and $\mathrm{P}<0.001$, respectively). However, non-HDL cholesterol and free fatty acids showed no significant changes during the 24 -week treatment period.

Changes in liver function tests, kidney function tests, and other laboratory parameters after initiation of ipragliflozin therapy are shown in Table 5. Alanine aminotransferase (ALT), aspartate transaminase (AST), and lactate dehydrogenase all displayed a significant decrease after 4 weeks of ipragliflozin therapy $(\mathrm{P}<0.01)$, and then decreased significantly further up to 24 weeks $(\mathrm{P}<0.001)$. In addition, the levels of $\gamma$-glutamyl transpeptidase (GTP) and alkaline phosphatase were both reduced significantly in week 4 and a significant decrease was maintained thereafter $(\mathrm{P}<0.001)$.

Blood urea nitrogen and serum creatinine were increased significantly in week $4(\mathrm{P}<0.001)$ and the higher levels were maintained until week 24. Uric acid displayed a significant decrease in week $4(\mathrm{P}<0.001)$, which was maintained until week $24(\mathrm{P}<0.001)$. The estimated glomerular filtration rate was also significantly reduced in week $4(\mathrm{P}<0.001)$. However, the 
Table 3. Changes in Body Composition after Initiation of Ipragliflozin Therapy

\begin{tabular}{|c|c|c|c|c|}
\hline & Week 0 & Week 4 & Week 12 & Week 24 \\
\hline Body weight, $\mathrm{kg}$ & $79.6 \pm 16.6$ & $\begin{array}{l}78.4 \pm 16.4 * * * \\
(-1.2 \pm 1.4)\end{array}$ & $\begin{array}{l}77.5 \pm 16.2 * * * \\
(-2.1 \pm 2.6)\end{array}$ & $\begin{array}{l}77.0 \pm 16.2 * * * \\
(-2.6 \pm 3.3)\end{array}$ \\
\hline Body fat mass, $\mathrm{kg}$ & $25.1 \pm 8.9$ & $\begin{array}{l}24.4 \pm 8.7 * * * \\
(-0.7 \pm 1.8)\end{array}$ & $\begin{array}{l}23.7 \pm 8.6^{* * *} \\
(-1.4 \pm 2.2)\end{array}$ & $\begin{array}{l}23.2 \pm 8.7 * * * \\
(-1.9 \pm 2.9)\end{array}$ \\
\hline Fat-free body mass, $\mathrm{kg}$ & $54.5 \pm 10.9$ & $\begin{array}{l}54.0 \pm 10.9 * * * \\
(-0.5 \pm 1.9)\end{array}$ & $\begin{array}{l}53.8 \pm 10.9 * * * \\
(-0.7 \pm 2.5)\end{array}$ & $\begin{array}{l}53.8 \pm 10.7 * * * \\
(-0.6 \pm 2.8)\end{array}$ \\
\hline Muscle mass, $\mathrm{kg}$ & $49.9 \pm 10.1$ & $\begin{array}{l}49.5 \pm 10.1 \text { *** } \\
(-0.4 \pm 1.9)\end{array}$ & $\begin{array}{l}49.4 \pm 10.1 \text { *** } \\
(-0.6 \pm 2.4)\end{array}$ & $\begin{array}{l}49.4 \pm 9.9 * * \\
(-0.5 \pm 2.6)\end{array}$ \\
\hline Body water mass, $\mathrm{kg}$ & $39.2 \pm 7.8$ & $\begin{array}{l}38.8 \pm 7.8^{* * *} \\
(-0.4 \pm 1.5)\end{array}$ & $\begin{array}{l}38.7 \pm 7.9 * * * \\
(-0.5 \pm 1.9)\end{array}$ & $\begin{array}{l}38.7 \pm 7.7 * * * \\
(-0.5 \pm 2.1)\end{array}$ \\
\hline Extracellular water mass, $\mathrm{kg}$ & $15.6 \pm 3.2$ & $\begin{array}{l}15.3 \pm 3.1 * * * \\
(-0.3 \pm 1.3)\end{array}$ & $\begin{array}{l}15.1 \pm 3.2 * * * \\
(-0.6 \pm 1.5)\end{array}$ & $\begin{array}{l}15.1 \pm 3.0 * * * \\
(-0.5 \pm 1.6)\end{array}$ \\
\hline Intracellular water mass, $\mathrm{kg}$ & $23.6 \pm 4.9$ & $\begin{array}{l}23.6 \pm 5.0 \\
(-0.1 \pm 1.6)\end{array}$ & $\begin{array}{l}23.7 \pm 5.1 \\
(0.0 \pm 1.8)\end{array}$ & $\begin{array}{l}23.6 \pm 5.0 \\
(-0.0 \pm 2.0)\end{array}$ \\
\hline Protein mass, $\mathrm{kg}$ & $10.7 \pm 2.3$ & $\begin{array}{l}10.7 \pm 2.3^{*} \\
(-0.1 \pm 0.5)\end{array}$ & $\begin{array}{l}10.7 \pm 2.3 \\
(-0.1 \pm 0.6)\end{array}$ & $\begin{array}{l}10.7 \pm 2.2 \\
(-0.1 \pm 0.7)\end{array}$ \\
\hline Mineral mass, $\mathrm{kg}$ & $4.5 \pm 0.9$ & $\begin{array}{l}4.5 \pm 0.9 * * * \\
(-0.1 \pm 0.1)\end{array}$ & $\begin{array}{l}4.4 \pm 0.9 * * * \\
(-0.1 \pm 0.2)\end{array}$ & $\begin{array}{l}4.4 \pm 0.9 * * * \\
(-0.1 \pm 0.2)\end{array}$ \\
\hline Muscle mass (trunk), $\mathrm{kg}$ & $24.3 \pm 4.9$ & $\begin{array}{l}24.1 \pm 4.9 * * * \\
(-0.2 \pm 0.8)\end{array}$ & $\begin{array}{l}24.0 \pm 4.9 * * * \\
(-0.3 \pm 1.0)\end{array}$ & $\begin{array}{l}24.0 \pm 4.8^{* * *} \\
(-0.3 \pm 1.1)\end{array}$ \\
\hline Muscle mass (upper limbs), kg & $3.47 \pm 0.75$ & $\begin{array}{l}3.45 \pm 0.76 \\
(-0.03 \pm 0.20)\end{array}$ & $\begin{array}{l}3.44 \pm 0.80 \\
(-0.04 \pm 0.34)\end{array}$ & $\begin{array}{l}3.44 \pm 0.76 \\
(-0.04 \pm 0.30)\end{array}$ \\
\hline Muscle mass (lower limbs), kg & $9.36 \pm 1.86$ & $\begin{array}{l}9.27 \pm 1.86^{* *} \\
(-0.09 \pm 0.47)\end{array}$ & $\begin{array}{l}9.27 \pm 1.88 * \\
(-0.09 \pm 0.57)\end{array}$ & $\begin{array}{l}9.28 \pm 1.84 \\
(-0.08 \pm 0.59)\end{array}$ \\
\hline Body mass index, $\mathrm{kg} / \mathrm{m}^{2}$ & $29.6 \pm 5.1$ & $\begin{array}{l}29.2 \pm 5.0 * * * \\
(-0.4 \pm 0.5)\end{array}$ & $\begin{array}{l}28.9 \pm 4.9 * * * \\
(-0.8 \pm 1.0)\end{array}$ & $\begin{array}{l}28.7 \pm 4.9 * * * \\
(-1.0 \pm 1.2)\end{array}$ \\
\hline Body fat percentage, $\%$ & $31.1 \pm 7.0$ & $\begin{array}{l}30.7 \pm 7.1 * * \\
(-0.4 \pm 2.1)\end{array}$ & $\begin{array}{l}30.2 \pm 7.2 * * * \\
(-1.0 \pm 2.4)\end{array}$ & $\begin{array}{l}29.6 \pm 7.3 * * * \\
(-1.5 \pm 3.2)\end{array}$ \\
\hline Visceral fat/subcutaneous fat ratio, $\%$ & $0.436 \pm 0.042$ & $\begin{array}{l}0.433 \pm 0.043 * * \\
(-0.003 \pm 0.017)\end{array}$ & $\begin{array}{l}0.428 \pm 0.045 * * * \\
(-0.008 \pm 0.020)\end{array}$ & $\begin{array}{l}0.424 \pm 0.048^{* * *} \\
(-0.012 \pm 0.026)\end{array}$ \\
\hline
\end{tabular}

$\mathrm{n}=373$. Data are shown as the mean \pm standard deviation. Analysis of variance vs. week $0,{ }^{* * *} \mathrm{P}<0.001,{ }^{* *} \mathrm{P}<0.01$, ${ }^{*} \mathrm{P}<0.05$

estimated glomerular filtration rate increased slightly in week 12 , and then showed a significant decrease from baseline in week $24(\mathrm{P}<0.05)$. Hematocrit was increased significantly in week 4, week 12, and week $24(\mathrm{P}<0.001)$.

Regarding changes in ion concentrations after the start of ipragliflozin therapy, $\mathrm{Na}^{+}$and $\mathrm{Cl}^{-}$both showed a transient significant increase in week 4 ( $\mathrm{P}<0.05$ and $\mathrm{P}<0.01$, respectively), but no significant changes in $\mathrm{Na}^{+}$and $\mathrm{Cl}^{-}$from the baseline were found subsequently. $\mathrm{K}^{+}$was increased significantly in week 24 $(\mathrm{P}<0.001), \mathrm{Ca}^{2+}$ did not change significantly during the administration period, and Pi was increased significantly in week 24 .

\section{Safety evaluation}

\section{Blood ketone bodies}

Blood ketone bodies increased by $0.12 \mathrm{mmol} / \mathrm{L}$ from the base- line value in week 4 and a significant change from baseline was observed at this time $(\mathrm{P}<0.05)$. Thereafter, similar levels of ketone bodies were maintained, although no significant changes were seen (Table 5).

AEs

AEs occurred in 106 of 451 patients (23.5\%). The chief AEs were vulvovaginal candidiasis in 14 patients (3.1\%); genital pruritus, upper respiratory tract inflammation, and cystitis in eight patients each (1.8\%); nasopharyngitis and bronchial infection in seven patients each $(1.6 \%)$; influenza in six patients $(1.3 \%)$; skin rash in five patients $(1.1 \%)$; and drug eruption and hypoglycemia in four patients each $(0.9 \%)$. ADRs were detected in 62 of the 451 patients $(13.7 \%)$. The main ADRs were as follows: vulvovaginal candidiasis in 14 patients (3.1\%); genital pruritus in eight patients $(1.8 \%)$; cystitis in seven patients $(1.6 \%)$; skin rash in four patients $(0.9 \%)$; drug eruption, dizzi- 
Table 4. Changes in Blood Pressure and Fasting Serum Lipids after Initiation of Ipragliflozin Therapy

\begin{tabular}{|c|c|c|c|c|c|}
\hline & $\mathbf{n}$ & Week 0 & Week 4 & Week 12 & Week 24 \\
\hline Systolic blood pressure, $\mathrm{mm} \mathrm{Hg}$ & 369 & $133.1 \pm 17.1$ & $\begin{array}{l}127.9 \pm 16.4 * * * \\
(-5.1 \pm 14.9)\end{array}$ & $\begin{array}{l}128.5 \pm 16.5^{* * * *} \\
(-4.5 \pm 16.1)\end{array}$ & $\begin{array}{l}128.2 \pm 16.8^{* * *} \\
(-4.9 \pm 16.8)\end{array}$ \\
\hline Diastolic blood pressure, $\mathrm{mm} \mathrm{Hg}$ & 369 & $79.1 \pm 10.9$ & $\begin{array}{l}76.5 \pm 10.8^{* * * *} \\
(-2.6 \pm 9.8)\end{array}$ & $\begin{array}{l}76.6 \pm 11.1^{* * *} \\
(-2.5 \pm 10.0)\end{array}$ & $\begin{array}{l}76.8 \pm 11.7 * * * \\
(-2.3 \pm 10.6)\end{array}$ \\
\hline Total cholesterol, mg/dL & 111 & $201.4 \pm 36.7$ & $\begin{array}{l}197.9 \pm 37.7 \\
(-3.5 \pm 25.0)\end{array}$ & $\begin{array}{l}201.6 \pm 35.8 \\
(0.2 \pm 26.0)\end{array}$ & $\begin{array}{l}203.3 \pm 38.9 \\
(1.9 \pm 29.0)\end{array}$ \\
\hline Low-density lipoprotein cholesterol, mg/dL & 100 & $117.0 \pm 29.9$ & $\begin{array}{l}116.9 \pm 31.9 \\
(-0.1 \pm 20.6)\end{array}$ & $\begin{array}{l}116.6 \pm 29.3 \\
(-0.3 \pm 24.7)\end{array}$ & $\begin{array}{l}117.5 \pm 31.6 \\
(0.5 \pm 26.7)\end{array}$ \\
\hline High-density lipoprotein cholesterol, mg/dL & 112 & $52.6 \pm 11.8$ & $\begin{array}{l}52.5 \pm 11.5 \\
(-0.2 \pm 5.7)\end{array}$ & $\begin{array}{l}56.5 \pm 18.8 \\
(3.9 \pm 16.6)\end{array}$ & $\begin{array}{l}57.7 \pm 16.5^{* * *} \\
(5.1 \pm 12.3)\end{array}$ \\
\hline Triglycerides, mg/dL & 112 & $164.1 \pm 101.7$ & $\begin{array}{l}145.6 \pm 95.0 * \\
(-18.5 \pm 65.1)\end{array}$ & $\begin{array}{l}140.8 \pm 92.6^{* *} \\
(-23.4 \pm 76.3)\end{array}$ & $\begin{array}{l}136.8 \pm 94.7 * * * \\
(-27.3 \pm 68.7)\end{array}$ \\
\hline $\begin{array}{l}\text { Non-high-density lipoprotein cholesterol, } \\
\mathrm{mg} / \mathrm{dL}\end{array}$ & 112 & $148.8 \pm 37.0$ & $\begin{array}{l}145.4 \pm 37.7 \\
(-3.3 \pm 23.4)\end{array}$ & $\begin{array}{l}145.1 \pm 36.5 \\
(-3.7 \pm 28.4)\end{array}$ & $\begin{array}{l}145.6 \pm 38.1 \\
(-3.1 \pm 30.0)\end{array}$ \\
\hline Free fatty acids, $\mu \mathrm{Eq} / \mathrm{L}$ & 112 & $712.4 \pm 259.1$ & $\begin{array}{l}755.2 \pm 253.1 \\
(42.8 \pm 239.8)\end{array}$ & $\begin{array}{l}719.1 \pm 288.1 \\
(6.7 \pm 309.8)\end{array}$ & $\begin{array}{l}732.5 \pm 287.2 \\
(20.1 \pm 253.3)\end{array}$ \\
\hline
\end{tabular}

Data are shown as the mean \pm standard deviation. Analysis of variance vs. week $0,{ }^{* * *} P<0.001,{ }^{* *} P<0.01,{ }^{*} P<0.05$.

ness, and hypoglycemia in three patients each $(0.7 \%)$; and hematocrit increased in two patients $(0.4 \%)$. Serious AEs occurred in eight of the 451 patients $(1.8 \%)$, including urinary tract infection, ketosis, and dehydration in one patient each $(0.2 \%)$.

\section{Discussion}

In the present study, T2DM patients with poor glycemic control received ipragliflozin as monotherapy or combination therapy for 24 weeks, and it was demonstrated that treatment with ipragliflozin improved both glycemic control (HbAlc and fasting/postprandial BG levels) and insulin resistance. Various other effects were also observed, including a decrease in BW, $\mathrm{BFM}$, body water mass, and WC; improvement of liver function tests (AST, ALT, and $\gamma$-GTP), serum lipids (triglycerides and HDL cholesterol), and the uric acid level; and reduction of the BP. During the study period, AEs occurred in 106 patients $(23.5 \%)$ and the most frequent AEs were genital infections.

The change in HbA1c after 24 weeks of ipragliflozin therapy in the present study was within the range of changes found in previous studies conducted by Kashiwagi et al (HbAlc: $-0.64 \%$ to $-0.87 \%$ ) $[9-11,13]$. Thus, the present large-scale study suggested that ipragliflozin is effective for controlling $\mathrm{BG}$ in the real-world clinical setting. Interestingly, the baseline $\mathrm{HbA} 1 \mathrm{c}$ value was inversely correlated with the change in HbA1c from baseline to week $12(\mathrm{r}=-0.652, \mathrm{P}<0.001)$ and week $24(\mathrm{r}=-0.696, \mathrm{P}<0.001)$. These correlations were stronger than the correlation reported by Kashiwagi et al ( $\mathrm{r}$ $=-0.438, \mathrm{P}<0.001$ ) [13]. Our previous multiple regression analysis also showed that the baseline HbAlc level had the largest impact on the change in HbA1c in week 12 [14], while the present study demonstrated that the baseline $\mathrm{HbA} 1 \mathrm{c}$ had the largest effect on the change in HbA1c in week 24 (data not shown). Other factors that had an influence on the change in
HbA1c from baseline to week 24 included the prescribing pattern at the start of administration (switching), the duration of diabetes, and the gender (data not shown). Regarding the prescribing pattern at the start of administration, switching from another antidiabetic agent to ipragliflozin may lead to deterioration of HbA1c. However, further long-term studies and more detailed analyses are needed to confirm this finding.

Insulin resistance, an indicator of pancreatic function, showed a significant improvement after 4 weeks of ipragliflozin therapy and this improvement was maintained until week 24. These results were in agreement with the findings of the ILLUMINATE study conducted by Kashiwagi et al [9]. It has been reported that ipragliflozin [15] and dapagliflozin [16] increase the disposition index in the 75-g glucose tolerance test, suggesting that improvement of $\beta$-cell function may be achieved with these medications. SGLT2 inhibitors improve glycemic control in an insulin-independent manner via enhancement of urinary glucose excretion, and improvement of insulin resistance would probably occur through an indirect action. Further research will be required to identify the mechanism by which SGLT2 inhibitors improve insulin resistance.

In this study, SUs, insulin, or TZDs (medications that can cause weight gain [17]) were used concomitantly with ipragliflozin by $36.7 \%, 21.5 \%$, and $13.7 \%$ of the patients, respectively. However, administration of ipragliflozin at $50 \mathrm{mg}$ daily for 24 weeks significantly decreased BW by $2.6 \mathrm{~kg}$ from baseline (the percent change in BW was $-3.2 \%$ ) and significantly decreased WC by $2.9 \mathrm{~cm}$ from baseline. The change in BW in this study was larger than in either ILLUMINATE or LANTERN, which evaluated the efficacy of ipragliflozin compared with placebo after administration for 24 weeks (BW was decreased by $1.8 \mathrm{~kg}$ and WC was decreased by $1.83 \mathrm{~cm}$ after administration of ipragliflozin) $[9,18]$. This difference in the change in BW may be explained by the larger BW and WC at baseline in the present study compared with the LANTERN study, rather 
Table 5. Changes in Other Parameters after Initiation of Ipragliflozin Therapy

\begin{tabular}{|c|c|c|c|c|}
\hline & Week 0 & Week 4 & Week 12 & Week 24 \\
\hline Alanine aminotransferase, IU/L & $39.8 \pm 30.3$ & $\begin{array}{l}36.6 \pm 28.4 * * \\
(-3.1 \pm 15.9)\end{array}$ & $\begin{array}{l}32.8 \pm 22.3 * * * \\
(-7.0 \pm 21.4)\end{array}$ & $\begin{array}{l}29.6 \pm 18.7 * * * \\
(-10.2 \pm 22.9)\end{array}$ \\
\hline Aspartate transaminase, IU/L & $32.4 \pm 24.7$ & $\begin{array}{l}30.5 \pm 23.1 * * \\
(-1.9 \pm 10.5)\end{array}$ & $\begin{array}{l}27.7 \pm 16.5 * * * \\
(-4.7 \pm 16.0)\end{array}$ & $\begin{array}{l}25.1 \pm 11.8 * * * \\
(-7.3 \pm 20.1)\end{array}$ \\
\hline Lactate dehydrogenase, IU/L & $202.7 \pm 41.7$ & $\begin{array}{l}196.4 \pm 40.9^{* *} \\
(-6.3 \pm 33.5)\end{array}$ & $\begin{array}{l}192.2 \pm 35.8^{* * *} \\
(-10.5 \pm 34.7)\end{array}$ & $\begin{array}{l}190.7 \pm 39.7 * * * \\
(-12.0 \pm 40.4)\end{array}$ \\
\hline$\gamma$-glutamyl transpeptidase, IU/L & $58.2 \pm 60.0$ & $\begin{array}{l}49.4 \pm 52.2 * * * \\
(-8.9 \pm 26.2)\end{array}$ & $\begin{array}{l}45.0 \pm 42.6 * * * \\
(-13.2 \pm 38.4)\end{array}$ & $\begin{array}{l}42.5 \pm 39.7 * * * \\
(-15.7 \pm 41.8)\end{array}$ \\
\hline Alkaline phosphatase, IU/L & $238.9 \pm 82.1$ & $\begin{array}{l}228.1 \pm 73.7 * * * \\
(-10.8 \pm 40.4)\end{array}$ & $\begin{array}{l}227.5 \pm 68.9 * * * \\
(-11.4 \pm 45.3)\end{array}$ & $\begin{array}{l}225.8 \pm 64.5^{* * *} \\
(-13.0 \pm 49.9)\end{array}$ \\
\hline Blood urea nitrogen, $\mathrm{mg} / \mathrm{dL}$ & $14.2 \pm 4.4$ & $\begin{array}{l}15.1 \pm 4.5 * * * \\
(0.9 \pm 3.2)\end{array}$ & $\begin{array}{l}15.3 \pm 4.3^{* * *} \\
(1.1 \pm 3.4)\end{array}$ & $\begin{array}{l}15.7 \pm 4.5 * * * \\
(1.5 \pm 3.6)\end{array}$ \\
\hline Serum creatinine, $\mathrm{mg} / \mathrm{dL}$ & $0.71 \pm 0.20$ & $\begin{array}{l}0.74 \pm 0.22 * * * \\
(0.03 \pm 0.09)\end{array}$ & $\begin{array}{l}0.72 \pm 0.21 * * \\
(0.02 \pm 0.08)\end{array}$ & $\begin{array}{l}0.73 \pm 0.21 * * \\
(0.02 \pm 0.10)\end{array}$ \\
\hline Uric acid, mg/dL & $5.4 \pm 1.2$ & $\begin{array}{l}4.9 \pm 1.3 * * * \\
(-0.4 \pm 0.9)\end{array}$ & $\begin{array}{l}5.0 \pm 1.2 * * * \\
(-0.4 \pm 0.8)\end{array}$ & $\begin{array}{l}4.9 \pm 1.2 * * * \\
(-0.4 \pm 0.9)\end{array}$ \\
\hline $\begin{array}{l}\text { Estimated glomerular filtration } \\
\text { rate, } \mathrm{mL} / \mathrm{min} / 1.73 \mathrm{~m}^{2}\end{array}$ & $84.0 \pm 21.5$ & $\begin{array}{l}80.8 \pm 21.9 * * * \\
(-3.2 \pm 10.2)\end{array}$ & $\begin{array}{l}82.4 \pm 21.4 * \\
(-1.7 \pm 10.4)\end{array}$ & $\begin{array}{l}82.3 \pm 21.3 * \\
(-1.7 \pm 10.8)\end{array}$ \\
\hline Hematocrit, \% & $43.4 \pm 4.1$ & $\begin{array}{l}44.5 \pm 4.3^{* * *} \\
(1.2 \pm 1.9)\end{array}$ & $\begin{array}{l}45.4 \pm 4.2 * * * \\
(2.1 \pm 2.4)\end{array}$ & $\begin{array}{l}45.5 \pm 4.1 * * * \\
(2.1 \pm 2.5)\end{array}$ \\
\hline $\mathrm{Na}^{+}, \mathrm{mEq} / \mathrm{L}$ & $140.50 \pm 2.25$ & $\begin{array}{l}140.80 \pm 2.02 * \\
(0.30 \pm 2.0)\end{array}$ & $\begin{array}{l}140.80 \pm 1.88 \\
(0.30 \pm 2.1)\end{array}$ & $\begin{array}{l}140.70 \pm 1.93 \\
(0.20 \pm 2.3)\end{array}$ \\
\hline $\mathrm{K}^{+}, \mathrm{mEq} / \mathrm{L}$ & $4.12 \pm 0.55$ & $\begin{array}{l}4.12 \pm 0.51 \\
(0.00 \pm 0.43)\end{array}$ & $\begin{array}{l}4.18 \pm 0.50 \\
(0.06 \pm 0.57)\end{array}$ & $\begin{array}{l}4.35 \pm 0.54 * * * \\
(0.23 \pm 0.73)\end{array}$ \\
\hline $\mathrm{Cl}^{-}, \mathrm{mEq} / \mathrm{L}$ & $102.3 \pm 2.9$ & $\begin{array}{l}102.8 \pm 2.8^{* *} \\
(0.5 \pm 2.3)\end{array}$ & $\begin{array}{l}102.5 \pm 2.6 \\
(0.2 \pm 2.5)\end{array}$ & $\begin{array}{l}102.5 \pm 2.7 \\
(0.2 \pm 2.6)\end{array}$ \\
\hline $\mathrm{Ca}^{2+}, \mathrm{mEq} / \mathrm{L}$ & $9.4 \pm 0.4$ & $\begin{array}{l}9.4 \pm 0.4 \\
(0.0 \pm 0.3)\end{array}$ & $\begin{array}{l}9.4 \pm 0.4 \\
(-0.0 \pm 0.4)\end{array}$ & $\begin{array}{l}9.4 \pm 0.4 \\
(0.0 \pm 0.3)\end{array}$ \\
\hline $\mathrm{Pi}, \mathrm{mg} / \mathrm{dL}$ & $3.3 \pm 0.6$ & $\begin{array}{l}3.5 \pm 0.6^{* * *} \\
(0.2 \pm 0.6)\end{array}$ & $\begin{array}{l}3.5 \pm 0.7 * * * \\
(0.2 \pm 0.6)\end{array}$ & $\begin{array}{l}3.4 \pm 0.6^{* *} \\
(0.1 \pm 0.6)\end{array}$ \\
\hline Blood ketone bodies, $\mathrm{mmol} / \mathrm{L}$ & $0.30 \pm 1.43$ & $\begin{array}{l}0.42 \pm 2.04 * \\
(0.12 \pm 0.65)\end{array}$ & $\begin{array}{l}0.43 \pm 2.34 \\
(0.14 \pm 0.95)\end{array}$ & $\begin{array}{l}0.44 \pm 2.69 \\
(0.14 \pm 1.27)\end{array}$ \\
\hline
\end{tabular}

$\mathrm{n}=357$. Results are shown as the mean \pm standard deviation. Analysis of variance vs. week $0,{ }^{* *} \mathrm{P}<0.001,{ }^{* *} \mathrm{P}<0.01,{ }^{*} \mathrm{P}<$ 0.05 .

than differences in antidiabetic agents used by the subjects at the start of ipragliflozin treatment, because the percentage of patients receiving combination therapy with ipragliflozin and a sulfonamide or TZD in LANTERN was about $44 \%$ and $13 \%$, respectively, which were similar to the percentages in this study. Multiple regression analysis demonstrated that the baseline BMI was a factor with a significant influence on the change in BW at week 24 (data not shown), and Kashiwagi et al reported that the decrease in BW was greater in patients whose baseline BMI was higher [13]. These results support the notion that baseline BW is important. In this study, there were no significant differences in changes in BW and WC between the patients receiving concomitant treatment with an SU, insulin, or a TZD and the patients receiving ipragliflozin without such concomitant drugs. However, our results suggested that the effect of ipragliflozin on BW and WC may be attenuated in patients receiving such concomitant treatment. Thus, the effect of ipragliflozin on BW may be larger in obese T2DM patients with a higher BMI and may be attenuated in patients receiving concomitant treatment with antidiabetic agents that can cause weight gain. It has been suggested that food intake may increase as compensation for calories lost due to urinary glucose excretion after initiation of treatment with SGLT2 inhibitors [19]. When ipragliflozin is used in the real-world clinical setting, dietary advice should be considered.

In this study, the effects of ipragliflozin on body composition were investigated by using a biological impedance method [12]. Of the reduction in BW after the start of ipragliflozin therapy, the percentage of the loss as BFM and fat-free body mass was $58 \%$ and $42 \%$ in week 4 and $75 \%$ and $25 \%$ in week 24 , respectively. Thus, BFM increased as a proportion of the total loss over time. On the other hand, with regard to the loss of fat- 
free body mass, muscle mass was a larger proportion of the loss than mineral mass because of extracellular water loss. Among total BW loss, extracellular water loss accounted for a larger proportion in the early stage of ipragliflozin treatment (week 4) than in week 24. As we reported previously, these changes in body composition were in accord with the results obtained by Bolinder et al, who evaluated changes in body composition after the administration of dapagliflozin by using dual-energy X-ray absorptiometry and magnetic resonance imaging [20, 21]. In the early stage of treatment with an SGLT2 inhibitor, the weight loss effect of the medication may be caused by a decrease in fluid volume resulting from osmotic diuresis due to accelerated urinary glucose excretion, while subsequent weight loss may be due to a decrease in body fat related to energy consumption. As we reported previously [12], SGLT2 inhibitors may influence clinical laboratory values (increasing hematocrit and blood urea nitrogen, and decreasing uric acid) by reducing the fluid volume. Therefore, increased fluid intake is required during administration of SGLT2 inhibitors.

Regarding the effect of ipragliflozin on the serum lipid profile, the triglyceride level showed a significant decrease from 4 weeks after initiation of ipragliflozin therapy, and the significant improvement was maintained until week 24 . After 24 weeks of ipragliflozin therapy, HDL cholesterol was increased significantly, whereas LDL cholesterol was unchanged. These results were in agreement with the findings of Kashiwagi et al [13]. It is suggested that SGLT2 inhibitors may decrease glucose utilization and may thus influence lipid metabolism, including enhanced lipolysis of triglycerides. Interestingly, the EMPA-REG OUTCOME study, which was a large-scale clinical trial of empagliflozin (another SGLT2 inhibitor), revealed that empagliflozin decreased cardiovascular mortality as well as overall mortality compared with placebo [22]. Given these previous findings and the improvement of serum lipids by ipragliflozin in the present study, the effect of ipragliflozin on arteriosclerosis should be investigated in the future.

In agreement with Kashiwagi et al [13], we found that administration of ipragliflozin for 24 weeks significantly improved liver function parameters (ALT and AST). It was reported that ipragliflozin decreases BW and improves fatty liver in obese mice and hepatic insufficiency in patients with T2DM [23]. Accordingly, it is possible that SGLT2 inhibitors may be useful for treating fatty liver in patients with T2DM.

During this study, AEs occurred in 106 out of 451 patients $(23.5 \%)$ and ADRs occurred in 62 out of 451 patients $(13.7 \%)$. Frequent ADRs were genital infections, including vulvovaginal candidiasis in 14 patients $(3.1 \%)$ and genital pruritus in eight patients $(1.8 \%)$. Compared with a study of ipragliflozin that was started within 3 months after launching this drug, in which ADRs were evaluated at 1 year [24], the incidence rate of genital infections was slightly higher in the present study. In fact, the third most common event in this study was genital infections $(1.45 \%)$, after skin rashes $(2.23 \%)$ and dehydration $(1.90 \%)$. A risk of diabetic ketoacidosis during treatment with SGLT2 inhibitors has been reported [25]. Clinical studies of these drugs have shown that the mean blood level of ketone bodies is increased [26-28]. In this study, the ketone body level also increased from 4 weeks after the start of ipragliflozin therapy.

The present study had several limitations. Several previous studies have demonstrated that ipragliflozin is more effective than placebo [9-11]. We performed a single-arm study without placebo control in the real-world clinical setting, which makes evaluation of the results somewhat more difficult. Second, there are many SGLT2 inhibitors and it is unclear whether efficacy and safety vary among these agents; hence, the results might have been different if another SGLT2 inhibitor had been used. Since all SGLT2 inhibitors have a similar chemical structure, the actual inhibitor used may not influence the efficacy and safety results, but further comparison of these agents is warranted. Finally, the body composition analyzer used in this study could not separately measure the visceral fat mass and subcutaneous fat mass in BFM.

In conclusion, 24 weeks of ipragliflozin treatment (monotherapy or concomitant therapy with another antidiabetic agent) improved glycemic control, serum lipids, liver function, and BP in T2DM patients with poor baseline glycemic control in the real-world clinical setting. Of the BW loss caused by ipragliflozin administration, $70 \%$ or more was due to body fat loss and only about $20 \%$ was accounted for by extracellular water loss. Further studies are warranted to evaluate the longterm efficacy and safety of ipragliflozin.

\section{Conflicts of Interest}

The authors declare no conflicts of interest.

\section{Grant Support}

This research was planned and designed by the investigators and was financially supported by Astellas Pharma, Inc. The company was not involved in the study design, patient enrollment, data aggregation and analysis, data interpretation, or preparation of this report.

\section{References}

1. Chao EC. SGLT-2 Inhibitors: A New Mechanism for Glycemic Control. Clin Diabetes. 2014;32(1):4-11.

2. Vallon $\mathrm{V}$. The mechanisms and therapeutic potential of SGLT2 inhibitors in diabetes mellitus. Annu Rev Med. 2015;66:255-270.

3. Nauck MA. Update on developments with SGLT2 inhibitors in the management of type 2 diabetes. Drug Des Devel Ther. 2014;8:1335-1380.

4. Inzucchi SE, Zinman B, Wanner C, Ferrari R, Fitchett D, Hantel S, Espadero RM, et al. SGLT-2 inhibitors and cardiovascular risk: proposed pathways and review of ongoing outcome trials. Diab Vasc Dis Res. 2015;12(2):90-100.

5. Scheen AJ. Pharmacodynamics, efficacy and safety of sodium-glucose co-transporter type 2 (SGLT2) inhibitors for the treatment of type 2 diabetes mellitus. Drugs. 2015;75(1):33-59.

6. Haas B, Eckstein N, Pfeifer V, Mayer P, Hass MD. Efficacy, safety and regulatory status of SGLT2 inhibitors: 
focus on canagliflozin. Nutr Diabetes. 2014;4:e143.

7. Kashiwagi A, Kazuta K, Yoshida S, Nagase I. Randomized, placebo-controlled, double-blind glycemic control trial of novel sodium-dependent glucose cotransporter 2 inhibitor ipragliflozin in Japanese patients with type 2 diabetes mellitus. J Diabetes Investig. 2014;5(4):382-391.

8. Kashiwagi A, Kazuta K, Takinami Y, Yoshida S, Utsuno A, Nagase I. Ipragliflozin improves glycemic control in Japanese patients with type 2 diabetes mellitus: the BRIGHTEN study. Diabetol Int. 2015;6(1):8-18.

9. Kashiwagi A, Kazuta K, Goto K, Yoshida S, Ueyama E, Utsuno A. Ipragliflozin in combination with metformin for the treatment of Japanese patients with type 2 diabetes: ILLUMINATE, a randomized, double-blind, placebo-controlled study. Diabetes Obes Metab. 2015;17(3):304-308.

10. Kashiwagi A, Shiga T, Akiyama N, Kazuta K, Utsuno A, Yoshida S, Uemiya E. Efficacy and safety of ipragliflozin as an add on to pioglitazone in Japanese patients with inadequately controlled type 2 diabetes: a randomized, double blind, placebo controlled study (the SPOTLIGHT study). Diabetol Int. 2015;6(2):104-116.

11. Kashiwagi A, Akiyama N, Shiga T, Kazuta K, Utsuno A, Yoshida S, Uemiya E. Efficacy and safety of ipragliflozin as an add on to a sulfonylurea in Japanese patients with inadequately controlled type 2 diabetes: results of the randomized, placebo controlled, double blind, phase III EMIT study. Diabetol Int. 2015;6(2):125-138.

12. Iizuka T, Iemitsu $\mathrm{K}$, Takihata $\mathrm{M}$, Takai M, Nakajima S, Minami N, Umezawa S, et al. Efficacy and Safety of Ipragliflozin in Japanese Patients With Type 2 Diabetes: Interim Outcome of the ASSIGN-K Study. J Clin Med Res. 2016;8(2):116-125.

13. Kashiwagi A, Yoshida S, Nakamura I, Kazuta K, Ueyama E, Takahashi H, Satomi H, et al. Efficacy and safety of ipragliflozin in Japanese patients with type 2 diabetes stratified by body mass index: A subgroup analysis of five randomized clinical trials. J Diabetes Investig. 2016;7(4):544-554.

14. Iemitsu K, Iizuka T, Takihata M, Takai M, Nakajima S, Minami N, Umezawa S, et al. Factors Influencing Changes in Hemoglobin A1c and Body Weight During Treatment of Type 2 Diabetes With Ipragliflozin: Interim Analysis of the ASSIGN-K Study. J Clin Med Res. 2016;8(5):373-378.

15. Takahara M, Shiraiwa T, Matsuoka TA, Katakami N, Shimomura I. Ameliorated pancreatic beta cell dysfunction in type 2 diabetic patients treated with a sodiumglucose cotransporter 2 inhibitor ipragliflozin. Endocr J. 2015;62(1):77-86.

16. Merovci A, Mari A, Solis C, Xiong J, Daniele G, ChavezVelazquez A, Tripathy D, et al. Dapagliflozin lowers plasma glucose concentration and improves beta-cell function. J Clin Endocrinol Metab. 2015;100(5):1927-1932.

17. Wilding JP. The importance of weight management in type 2 diabetes mellitus. Int J Clin Pract. 2014;68(6):682691.

18. Kashiwagi A, Takahashi H, Ishikawa H, Yoshida S, Kazu- ta K, Utsuno A, Ueyama E. A randomized, double-blind, placebo-controlled study on long-term efficacy and safety of ipragliflozin treatment in patients with type 2 diabetes mellitus and renal impairment: results of the long-term ASP1941 safety evaluation in patients with type 2 diabetes with renal impairment (LANTERN) study. Diabetes Obes Metab. 2015;17(2):152-160.

19. Ferrannini G, Hach T, Crowe S, Sanghvi A, Hall KD, Ferrannini E. Energy Balance After Sodium-Glucose Cotransporter 2 Inhibition. Diabetes Care. 2015;38(9):1730-1735.

20. Bolinder J, Ljunggren O, Kullberg J, Johansson L, Wilding J, Langkilde AM, Sugg J, et al. Effects of dapagliflozin on body weight, total fat mass, and regional adipose tissue distribution in patients with type 2 diabetes mellitus with inadequate glycemic control on metformin. J Clin Endocrinol Metab. 2012;97(3):1020-1031.

21. Bolinder J, Ljunggren O, Johansson L, Wilding J, Langkilde AM, Sjostrom CD, Sugg J, et al. Dapagliflozin maintains glycaemic control while reducing weight and body fat mass over 2 years in patients with type 2 diabetes mellitus inadequately controlled on metformin. Diabetes Obes Metab. 2014;16(2):159-169.

22. Zinman B, Wanner C, Lachin JM, Fitchett D, Bluhmki E, Hantel S, Mattheus M, et al. Empagliflozin, Cardiovascular Outcomes, and Mortality in Type 2 Diabetes. N Engl J Med. 2015;373(22):2117-2128.

23. Komiya C, Tsuchiya K, Shiba K, Miyachi Y, Furuke S, Shimazu N, Yamaguchi S, et al. Ipragliflozin Improves Hepatic Steatosis in Obese Mice and Liver Dysfunction in Type 2 Diabetic Patients Irrespective of Body Weight Reduction. PLoS One. 2016;11(3):e0151511.

24. Terauchi Y, Yokote K, Nakamura I, Sugamori H. Safety of ipragliflozin in elderly Japanese patients with type 2 diabetes mellitus (STELLA-ELDER): Interim results of a post-marketing surveillance study. Expert Opin Pharmacother. 2016;17(4):463-471.

25. Peters AL, Buschur EO, Buse JB, Cohan P, Diner JC, Hirsch IB. Euglycemic Diabetic Ketoacidosis: A Potential Complication of Treatment With SodiumGlucose Cotransporter 2 Inhibition. Diabetes Care. 2015;38(9):1687-1693.

26. Okamoto A, Yokokawa H, Sanada H, Naito T. Changes in Levels of Biomarkers Associated with Adipocyte Function and Insulin and Glucagon Kinetics During Treatment with Dapagliflozin Among Obese Type 2 Diabetes Mellitus Patients. Drugs R D. 2016;16(3):255-261.

27. Seino Y, Kaku K, Inagaki N, Haneda M, Sasaki T, Fukatsu A, Ubukata M, et al. Fifty-two-week long-term clinical study of luseogliflozin as monotherapy in Japanese patients with type 2 diabetes mellitus inadequately controlled with diet and exercise. Endocr J. 2015;62(7):593603.

28. Inagaki N, Kondo K, Yoshinari T, Kuki H. Efficacy and safety of canagliflozin alone or as add-on to other oral antihyperglycemic drugs in Japanese patients with type 2 diabetes: A 52-week open-label study. J Diabetes Investig. 2015;6(2):210-218. 